\title{
A problem with the recognition of penicillin-resistant pneumococci
}

\author{
T REES* AND PAMELA M WATERWORTH† \\ From the *Institute of Laryngology and Otology, Grays Inn Road, London WC1X 8EE, and \\ $\dagger$ Department of Clinical Microbiology, University College Hospital, London WCIE 6AU, UK
}

SUMmARY A strain of Streptococcus pneumoniae requiring $0.25 \mathrm{mg} / 1$ penicillin to inhibit its growth was isolated from the antrum of a child who had no history of either foreign contacts or previous treatment with penicillin. The penicillin resistance was recognised by chance because the disc used contained substantially less than its stated content of 1.5 unit. When discs containing 2 units were used there was little reduction in the size of the zone of inhibition.

It is now generally accepted that it can no longer be assumed that Streptococcus pneumoniae is sensitive to penicillin and that sensitivity tests must therefore be done. Despite this there have been only three reports of the isolation of resistant strains in this country. ${ }^{1-3}$ We report a fourth, together with evidence suggesting that some of these organisms may pass unrecognised.

\section{Clinical history}

An asthmatic 5-year-old English boy presented with a history of intermittent hoarseness and headaches over a period of four months. On examination the nasal septum was found to be thickened and the postnasal space was slightly narrowed. Both antra were opaque on sinus $x$-ray. The chest $x$-ray was normal. There was no clinical evidence of immunodeficiency. He was admitted to hospital for three days, during which bilateral antral washouts were done. A heavy pure growth of Haemophilus influenzae was isolated from the washings of the left antrum.

The patient was seen again after six weeks, during which time he had received no antibacterial drugs. He was readmitted to hospital for $\mathbf{4 8}$ hours, and a repeat left antral washout yielded a heavy growth of $H$. influenzae and Strep. pneumoniae. After discharge from hospital he was given a course of cotrimoxazole, and when seen some eight weeks later he was well. Nose and throat swabs were taken at this time from both the patient and his mother, but no pneumococci were isolated.

Received for publication 20 March 1980

\section{Sensitivity tests}

The original sensitivity test was performed with a disc containing 1.5 unit penicillin, and the organism gave only a very small zone of inhibition (about $3 \mathrm{~mm}$ from the edge of the disc). The test was repeated using a disc from a different batch containing 1 unit, and this produced a large zone not obviously smaller than that of the control staphylococcus. It was thus obvious, and was subsequently confirmed, that the original disc had deteriorated and contained considerably less than the stated 1.5 units.

The pneumococcus was then tested by the Stokes 4 method on Oxoid Isosensitest agar containing 4\% lysed horse blood, using the two discs containing 1 and ' 1.5 ' unit, together with a third containing 2 units. After overnight incubation there was again only a small zone of $2 \mathrm{~mm}$ round the ' 1.5 ' unit disc (control zone $9 \mathrm{~mm}$ ). In contrast, with the discs containing 1 and 2 units the zones produced by the pneumococcus were respectively only $4 \mathrm{~mm}$ and $3 \mathrm{~mm}$ smaller than those given by the control. Thus, although this strain should be classed as only moderately sensitive when tested with the 1 unit disc, it would justifiably be classed as sensitive with the higher content disc (Fig. 1a). However, if the plate was examined by transmitted light there was a broad band of haemolysis and lysed colonies inside the two larger zones (Fig. 1b). Nevertheless, it is customary to measure zones from visible colonies. The experiment was repeated, and the zones were measured after both 7 and 24 hours' incubation. After 7 hours the zones around all three discs were 


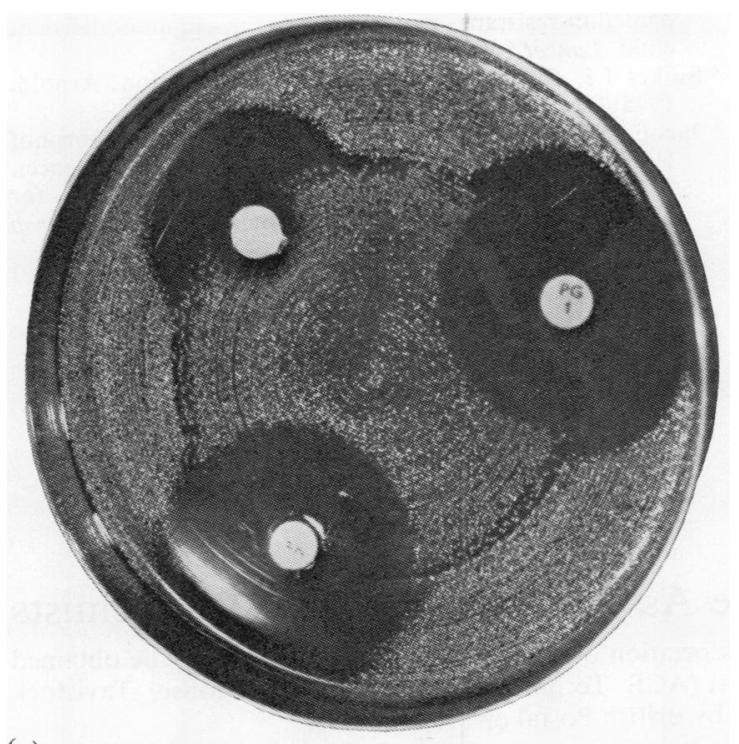

(a)

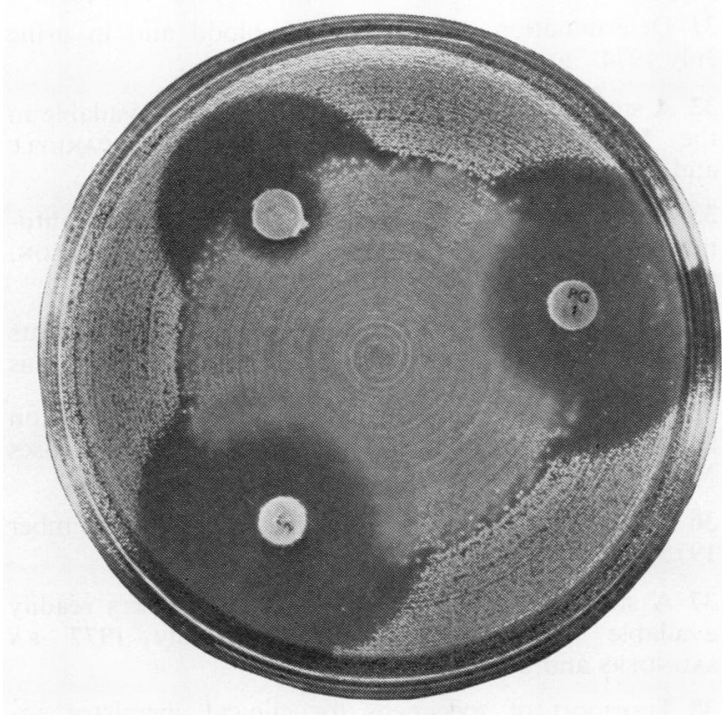

(b)

Fig. 1 Stokes test, on Oxoid Isosensitest agar $+5 \%$ lysed horse blood, comparing the sensitivity of the strain of Strep. pneumoniae (centre area) to that of the Oxford Staph. aureus (outer area). Discs contain: $P G 1=1$ unit penicillin: $P 2=2$ units penicillin: unlabelled disc $=$ ' 1.5 ' unit penicillin. (a) Photographed by reflected light. The apparent distortion of the zones is caused by the angle from which the picture was taken. (b) Photographed by transmitted light. Note the absence of colonies in the band of lysis within the larger zones. clear with well-defined edges and measured 3,7 , and $8 \mathrm{~mm}$ respectively. When examined the next day, that around the ' 1.5 ' unit disc showed little change but those around the discs containing 1 and 2 units had increased to 11 and $13 \mathrm{~mm}$ respectively, leaving an inner zone of haemolysis and lysed colonies. The staphylococcus control showed a $2 \mathrm{~mm}$ increase with both these discs.

The minimum inhibitory concentration (MIC) of penicillin for this strain of Strep. pneumoniae was determined by the plate dilution method using Oxoid Isosensitest agar with $5 \%$ lysed horse blood added and was found to be $0.25 \mathrm{mg} / \mathrm{l}$, compared to a control strain of $0.015 \mathrm{mg} / \mathrm{l}$. It was resistant to tetracycline by the disc test but sensitive to erythromycin and chloramphenicol.

\section{Discussion}

Penicillin-resistant pneumococci are apparently still very rare in this country, but the isolation of the present strain from a child with no history of previous penicillin treatment or foreign contacts infers that these strains may be present in the community. It is just possible that the patient acquired this strain by cross-infection during his brief stay in hospital, but, if so, the source has not been identified. No other comparable pneumococci have been isolated during routine microbiological studies up to the time of writing. It also seems possible that some strains may pass undetected. Several warnings have been given that these strains may not readily be recognised if high-content discs (10 units) are used, but it now seems that strains with moderate resistance may be difficult to recognise even when the customary low content disc is used. Certainly it seems possible that the present strain might have been missed but for the reduced disc content.

In a recent very extensive study of this subject in South Africa, Jacobs et al. ${ }^{5}$ obtained the best differentiation between sensitive, moderately resistant (MIC 0.1-1.0 mg/l), and resistant (MIC $>1.0$ $\mathrm{mg} / \mathrm{l})$ strains with discs containing $0.15 \mu \mathrm{g}(0.25$ units), which may well be about the level of our ' 1.5 ' unit disc. It should also be remembered that Strep. pneumoniae will normally give a zone slightly larger than the Oxford staphylococcus, and any reduction in zone size must therefore be looked at critically. Nevertheless discs containing 2 units penicillin are clearly unsatisfactory for detecting resistance in Strep. pneumoniae.

We are grateful to $\mathrm{Mr} \mathrm{R}$ Pracy, under whose care the patient was admitted, and to the MLSOs of the Bacteriology Laboratory of the Institute of Laryngology. 
The photographs were taken by $\mathrm{Mr} \mathbf{P}$ Luton, electron microscopist at University College Hospital.

\section{References}

${ }^{1}$ Howes VJ, Mitchell RG. Meningitis due to relatively penicillin-resistant pneumococcus. Brit Med J 1976; $1: 996$.

${ }^{2}$ Meers PD, Matthews RB. Multiply resistant pneumococcus. Lancet 1979;2:219.

${ }^{3}$ Shanson DC, Rees T, Sinclair L. Ear infection due to penicillin-resistant pneumococcus in immunodeficient child. Lancet 1979;2:956.

${ }^{4}$ Stokes EJ. Clinical Bacteriology. 4th ed. London: Arnold, $1975 ; 216$.

${ }^{5}$ Jacobs MR, Gaspar MN, Robins-Browne RM, Koornhof HJ. Antimicrobial susceptibility testing of pneumococci. 2. Determination of optimal disc diffusion test for detection of penicillin $\mathrm{G}$ resistance. $J$ Antimicrob Chemother 1980;6:53-64.

Reprints of this article will not be available from the author.

\section{Reports and Bulletins prepared by the Association of Clinical Biochemists}

The following reports and bulletins are published by the Association of Clinical Biochemists. They may be obtained from The Publishing Department, British Medical Journal (ACB Technical Bulletins), BMA House, Tavistock Square, London WC1H 9JR. Overseas readers should remit by British Postal or Money Order.

SCIENTIFIC REVIEWS (price $£ 1 \cdot 00 / \$ 2.00$ each)

1 The assessment of thyroid function March 1971 FV FLYNN and JR HOBBS

2 Renal function tests suitable for clinical practice January 1972 FL MITCHELL, N VEALL, and RWE WATTS

3 Biochemical tests for the assessment of fetoplacental function May 1975 CE WILDE and RE OAKEY

4 Test of exocrine pancreatic function March 1977 AH GOWENLOCK

5 Assay of cholinesterase in clinical chemistry March 1979 ELSIE SILK, J KING, and MARY WHITTAKER

TECHNICAL BULletins (price $£ 1 \cdot 00 / \$ 2.00$ each)

22 Bilirubin standards and the determination of bilirubin by manual and technicon AutoAnalyzer methods January 1971 BARBARA BILLING, RUTH HASLAM, and N WALD

23 Interchangeable cells for spectrophotometers and fluorimeters September 1971 SS BROWN and AH GOWENLOCK

24 Simple tests to detect poisons March 1972 BW MEADE et al.

25 Blood gas analysers May 1972 K DIxON

26 Kits for enzyme activity determination September 1972 SB ROSALKI and D TARLOW

27 Assessment of pumps suitable for incorporation into existing continuous flow analytical systems November 1972 A FLECK et al.

28 Routine clinical measurements of transferrin in human serum September 1973 K DIXON
29 Control materials for clinical biochemistry (5th edition) September 1973 JF STEVENS

30 Notes on the quality of performance of serum cholesterol assays September 1973 ss BROWN

31 Determination of uric acid in blood and in urine July 1974 RWE WATTS

32 A survey of amino acid analysers readily available in the United Kingdom September 1974 JE CARLYLE and P PURKISS

33 Definitions of some words and terms used in automated analysis November 1974 A FLECK, R ROBINSON, SS BROWN, and JR HOBBS

34 Measurement of albumin in the sera of patients January 1975 LINDA SLATER, PM CARTER, and JR HOBBS

35 Investigation of the validity of temperature correction factors for serum aspartate and alanine transaminases March 1975 SB ROSALKI et al.

36 Factors influencing the assay of creatinine November 1975 JGH COOK

37 A survey of enzyme reaction rate analysers readily available in the United Kingdom July 1977 RA SAUNDERS and RF BURNS

38 Transport of specimens for clinical chemistry analysis November 1977 P WILDING, JF ZILVA, and CE WILDE

39 A scheme for the evaluation of diagnostic kits May 1978 PH LLOYD

40 A practical guide to gamma-counting in radioimmunoassay January 1980 CE WILDE and D OTTEWELL

41 The use of biochemical tests in the diagnosis of disorders of calcium metabolism July 1980 ANGELA FAIRNEY 